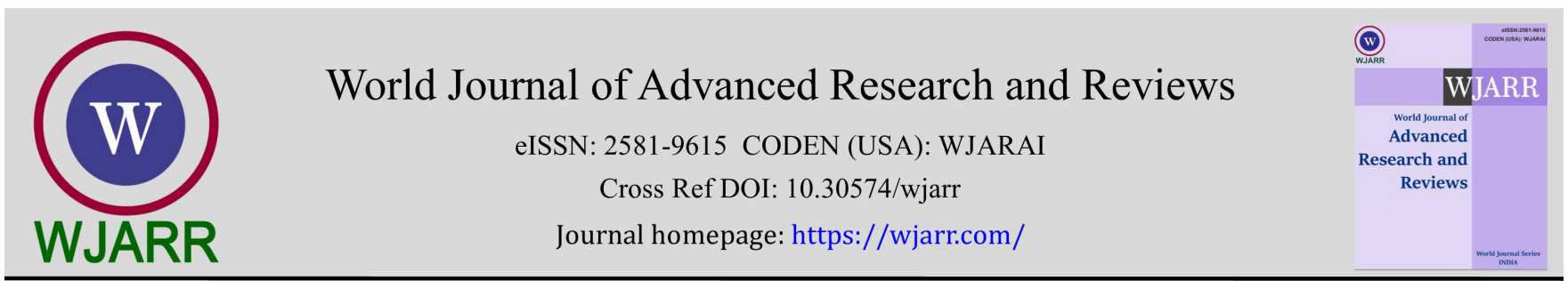

(RESEARCH ARTiClE)

\title{
Dietary practices associated with prevalence of malnutrition among the elderly in Kiambu County, Kenya
}

\author{
Wambui Mary Kamwana *, Job Mapesa and Naftali Oirere \\ Department of Public Health Human Nutrition and Dietetics, Kenya Methodist University, Nairobi, Kenya.
}

World Journal of Advanced Research and Reviews, 2021, 11(03), 453-461

Publication history: Received on 24 August 2021; revised on 28 September 2021; accepted on 30 September 2021

Article DOI: https://doi.org/10.30574/wjarr.2021.11.3.0494

\begin{abstract}
Ageing is often associated with various needs as well as changes, which make elderly people susceptible to malnutrition. A healthy diet helps to protect against malnutrition in all its forms, as well as noncommunicable diseases. Malnutrition is a major risk factor of cardiovascular and metabolic diseases and therefore the importance of good dietary practices and balanced diet cannot be overemphasized. The percentage of older people at risk of malnutrition in most Kenyan Counties has increased to $29.6 \%$ from $20.1 \%$ in 2015 . This study therefore study sought to assess the effect of dietary practices on malnutrition among the elderly in Kiambu County. The research design was cross sectional descriptive research design. The target population in this study was the elderly population from the age of 60 years and above. A sample of 398 respondents was determined with the help of Yamane Formula. A questionnaire was used to collect data. Descriptive, chi-square and correlation analysis were conducted with the help of SPSS. Results showed that prevalence of malnutrition stands at $42 \%$. Results also showed poor dietary practices. Only $26.6 \%$ of the sample had 3 meals per day. The results showed that gender $(p=0.000)$ and education level $(p=0.035)$ were significant. Results also showed that skipping of meals $(p=0.003)$ and number of meals $(p=0.042)$ were significant. Cross tabulation showed that respondents who had less than 3 meals and who skipped at least one meal were more likely to be malnourished. The study concluded that the high prevalence of malnutrition in the sample can be attributed to poor dietary practices. This study recommended an increase in food supplementation efforts by the county government to old people.
\end{abstract}

Keywords: Malnutrition of the Elderly; Nutrition status; Geriatric nutrition; Dietary practices; Ageing

\section{Introduction}

Malnutrition is a term used to describe a lack of balance in nutrients consumed by an individual (Chalermsri et al., 2020). Malnutrition among the elderly people often occurs due to functional and physiological changes that come with old age, inadequate access to food, and lack of financial support. The functional status of the elderly is their capability to carry out their everyday activities, which consists of food preparation and intake thus, affecting their nutritional status (Ramya, Ranganath, Jadhav, \& Swetha, 2017). There is a perception that malnutrition among the elderly people is most common in hospitals and institutions for the elderly, however, that is not the case as malnutrition is most common for elderly people who are at home. They tend to be given less attention due to the necessities that come with taking care of them. For the healthy elderly people, intervention is also required since they tend to have poor diets hence, low intake of nutrients, which can lead to future complication (Nyberg, Olsson, Pajalic, Örtman, Andersson, \& Blücher, 2015).

Ageing is often associated with various physiological, social, pathological, and psychological needs as well as changes, which make elderly people susceptible to malnutrition (Chalermsri et al., 2020). Traditionally, intake of food tends to decrease as one advance in age subsequently, in order to compensate for the diminished energy needs that are associated with lowered basal metabolic rate and physical activity, care for the elderly is imperative. Ageing is

\footnotetext{
${ }^{*}$ Corresponding author: Wambui Mary Kamwana

Department of Public Health Human Nutrition and Dietetics, Kenya Methodist University, Nairobi, Kenya.
} 
associated with health deterioration due to decreased resistance to diseases in the body. The cumulative effect of the interaction between decrease in nutrition and changes witnessed in ageing results in progressive under-nutrition which often goes undiagnosed among the elderly (Ghimire, Baral, \& Callahan, 2017). Nutrition among the elderly persons is associated with the quality of life (QoL) and functional quality.

Malnutrition is a major risk factor of cardiovascular and metabolic diseases and therefore the importance of good dietary practices and balanced diet cannot be overemphasized (Bede et al., 2020). Numerous scientific evidence points out on the importance of an individual's dietary practices and nutritional status in the prevention and management of multiple diseases. A healthy diet helps to protect against malnutrition in all its forms, as well as noncommunicable diseases (NCDs), including such as diabetes, heart disease, stroke and cancer. Dietary practice is defined as an observable actions or behavior of dietary habit and can be classified as good dietary practices and poor dietary practices (Nana \& Zema, 2018). They are the quantities, proportions, variety or combinations of different foods and beverages in diets, and the frequency with which they are habitually consumed. They can also be referred to as the habitual decisions of individuals or group of people regarding what foods they eat. According to Reddy and Anitha (2015), dietary practices are one of the most complex aspects of human behavior, being determined by multiple motives and directed and controlled by multiple stimuli. There are many potential influences on dietary practices including individual factors, families and friends, community characteristics, the food and supplement industry, and public policy (Krishnamoorthy et al., 2018).

Proper dietary choices require the consumption of vitamins, minerals, carbohydrates, proteins and fats (Zainudin et al., 2019). Maintaining a nutrient-dense diet is critically important for older adults because of the impact of food intake on health. In the elderly, there are increased requirements for a number of nutrients, such as: protein, riboflavin, vitamin B6, calcium, vitamin D and, for some, vitamin B12 (Bede et al., 2020). WHO recommendations include the consumption of five or more servings of fruits and vegetables per day (400-500g/day) and limited intake of saturated fats. According to Govindaraju et al. (2018), a dietary pattern consistent with current guidelines to consume relatively high amounts of vegetables, fruit, whole grains, poultry, fish, and low-fat dairy products may be associated with superior nutritional status, quality of life and survival in older adults. Fruit juices, milk and plant beverages are some of the drinks included in nutrition in the elderly guidelines (Franca et al., 2016).

Available evidence suggests that the elderly have poor dietary practices. According to Franca et al. (2016), the failure to meet the recommended intakes of fruit, vegetables, and fish and to avoid red meat with visible fat and chicken skin are indicators of unhealthy eating habits. National surveys and observational cohort studies have identified several nutrients that may be inadequately consumed in relation to health risk among older adults, including protein, $\mathrm{n}-3 \mathrm{FAs}$, dietary fiber, carotenoids (vitamin A precursors), calcium, magnesium, potassium, and vitamins B-6, B-12, D, and E (Shlisky et al., 2017). Krok-Schoen et al. (2018) found that dietary protein intakes were significantly lower in older age groups, with up to $46 \%$ of the oldest adults not meeting the protein intake recommendation. In a study conducted in Meru in Kenya, Munoru (2018) found that the mean energy intake was $1587 \pm 653$ for men and $1442 \pm 590$ for women which is below the WHO recommendations.

The percentage of older people at risk of malnutrition in most Kenyan Counties has increased to $29.6 \%$ from $20.1 \%$ in 2015 (Kuria, Waudo, \& Shikuri, 2016). Munoru (2018) found that 39.4\% elderly persons were undernourished in Meru County. In Uasin Gishu County, Bore et al. (2019) estimated the prevalence of undernutrition to be 41 percent. This may be due to their poor dietary practices. However, most nutrition interventions have focused on under-five children and women of reproductive age, particularly pregnant and lactating women leaving out the elderly, who are also vulnerable to malnutrition. Identifying factors that affect the dietary practices of the elderly is important to initiate timely and appropriate interventions. This study therefore sought to assess the effect of dietary practices on malnutrition among the elderly in Kiambu County.

\section{Material and methods}

The research design was cross sectional descriptive research design. Cross- sectional study design was appropriate in this study as it allowed for the collection of data at one point. It also allowed the researcher to determine the sociodemographic characteristics at the point of data collection. This allowed for the descriptive characteristics of respondents to be determined. The study area was Kiambu county which has a population of 596,268 (Male - 49\%, Female - $51 \%$ ). The main economic activity in Kiambu County is agriculture in tea, coffee, dairy, poultry and horticulture farming. Agriculture is the predominant economic activity in the county and contributes 17.4 per cent of the county's population income. Majority of the people in the county depend on the sub sector for their livelihood, with $1.28 \mathrm{M}$ directly or indirectly employed in the sector. The size of arable land in the county is 1,878.4 Km2, non-arable land is $649.7 \mathrm{Km} 2$ and $15.5 \mathrm{Km} 2$ is under water mass. 
The target population in this study was the elderly population from the age of 60 years and above. Estimated figures that included those that are above sixty years old was ninety two thousand five hundred and ninety two persons $(92,592)$ (County Government of Kiambu, 2018). To determine the sample population needed to participate in the study and allow proper inference of results to a wider population (among the elderly); Yamane (1967) formula was used.

$$
\begin{gathered}
n=\frac{92,592}{1+92592(0.05)^{2}} \\
n=398.27 \\
n=398
\end{gathered}
$$

Thus the researcher was to approach 398 respondents. Random sampling which is a probability sampling technique ensured that every elderly person aged above 60 years and residing in Kiambu had an equal opportunity to be selected to participate in the study. Simple randomization was used to prevent the selection bias and insures against accidental bias. A semi-structured, researcher administered questionnaire was used to collect data. The Mini Nutritional Assessment (MNA) a validated nutrition screening and assessment tool that identifies elderly people who are malnourished or at risk of malnutrition was used. The sum of the MNA score distinguishes between elderly patients with: 1) adequate nutritional status, MNA > or $=24 ; 2$ ) protein-calorie malnutrition, $M N A<17 ; 3$ ) at risk of malnutrition, MNA between 17 and 23.5. The Dietary Questionnaire that was adopted for this study mainly focused on the frequency of meals that the respondents took. The Dietary Questionnaire that was adopted for this study mainly focused on the frequency of meals that the respondents took. It also assessed whether they were allergic to particular foods and their preparation (with regards to who prepared the meals for them). It also looked at whether they were aware the nutritional requirements that they needed in their body. A pre- test of the socio-demographic questionnaire was done to ensure that the tool captured all the data that was needed from the respondent.

The study was carried out for 6 months between 2019 and 2020. An Ethical clearance was obtained from the Scientific and Ethics Review Committee at Kenya Methodist University. Permission to collect data was sought from the Kiambu County government. Participation was voluntary through informed consent after the respondents had been explained to the purpose of the study. An informed written or a thumb print consent was sought from the respondents. The respondents were assured of confidentiality of the information given before carrying out the study in order to enhance the response. Privacy was enhanced by not recording the name of the respondents anywhere. The respondents were made aware that the information given was for study purposes only and confidentiality, privacy, and dignity of the subjects were ensured.

Data analysis was done using the statistical package for social science (SPSS), version 24.0. Descriptive statistics namely frequencies and percentages were used to represent the prevalence of malnutrition and to describe the characteristics of the sample population. Chi Square tests were used to check for associations between demographic characteristics and malnutrition as well as between dietary practices and malnutrition. Results were presented in from of tables and pie-charts.

\section{Results}

The target population for the study was three hundred and ninety eight (398) respondents as calculated. The response rate was $68.8 \%$ representing 274 respondents.

\subsection{Social Demographic Characteristics of the Respondents}

Most (50.4\%) of the participants were male, married (48.5\%) with tertiary level education (30.7\%). Results also show that $57.7 \%$ were unskilled whereby $26.6 \%$ were self-employed and $22.3 \%$ were homemakers. 
Table 1 Social Demographic Characteristics of the Respondents

\begin{tabular}{|l|l|}
\hline Variables & \%(n) \\
\hline N=274 & $100(274)$ \\
\hline Gender & $50.4(138)$ \\
\hline Male & $49.6(136)$ \\
\hline Female & \multicolumn{2}{|l|}{} \\
\hline Marital Status & $48.5(133)$ \\
\hline Married & $20.4(56)$ \\
\hline Separated & $15.0(41)$ \\
\hline Widowed & $9.5(26)$ \\
\hline Never married & $6.6(18)$ \\
\hline Widower & \multicolumn{2}{|l|}{} \\
\hline Education level & $26.6(73)$ \\
\hline No formal schooling & $14.6(40)$ \\
\hline Primary level & $28.1(77)$ \\
\hline Secondary level & $30.7(84)$ \\
\hline Tertiary level & $19.3(53)$ \\
\hline Occupation in Early years & $26.6(73)$ \\
\hline Skilled & $22.3(61)$ \\
\hline Unskilled & $19.7(54)$ \\
\hline Professional & $12.0(33)$ \\
\hline Others & $57.7(158)$ \\
\hline Current occupation & $24.8(68)$ \\
\hline Farmer & $10.6(29)$ \\
\hline Business person & \multicolumn{2}{|l}{} \\
\hline Homemaker & \\
\hline Taking care of grandchildren & \\
\hline None & \\
\hline
\end{tabular}

\subsection{Prevalence of Malnutrition among Respondents}

The prevalence of malnutrition among respondents was established using through mini nutritional assessment (MNA). Results in Table 4.2 show that $42 \%$ of the respondents had between 0-7 points in the MNA score.

Table 2 Mini Nutritional Assessment Scores

\begin{tabular}{|c|c|c|}
\hline Points & Frequency & Percent (\%) \\
\hline $0-7$ & 115 & 42.0 \\
\hline $8-11$ & 61 & 22.3 \\
\hline $12-14$ & 98 & 35.8 \\
\hline Total & 274 & 100.0 \\
\hline
\end{tabular}


The sum total of the responses' assigned scores in Table 2 were then classified as follows to determine the prevalence of malnutrition: [(12-14 points is classified as having normal nutrition status), (8-11 points is classified as being at risk of malnutrition) and (0-7 points is classified as being malnourished).The prevalence of malnutrition therefore stands at $42 \%$ as shown in Figure 1.

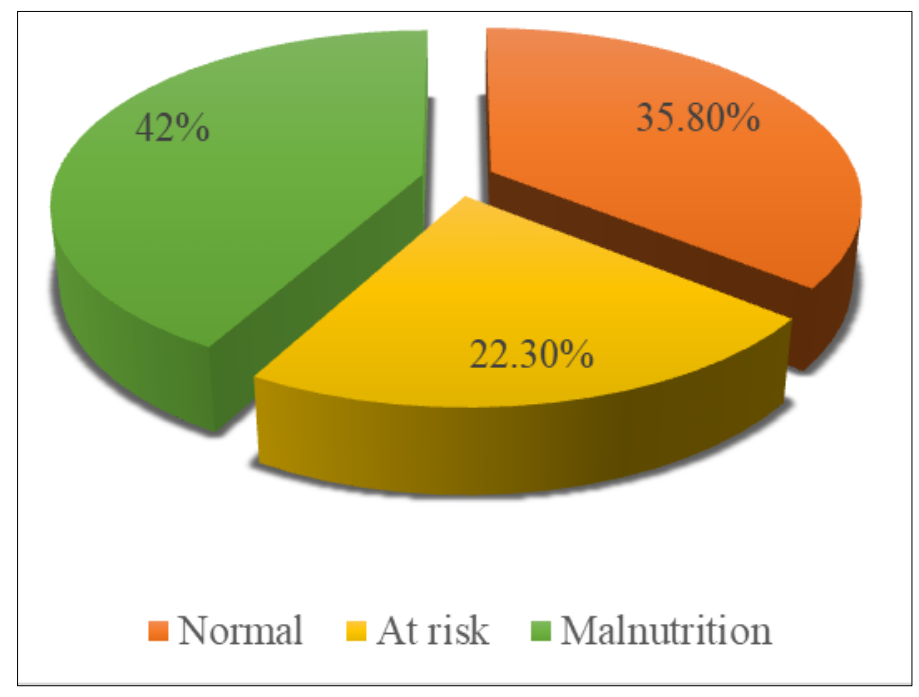

Figure 1 Prevalence of Malnutrition in Kiambu County

\subsection{Dietary Practices}

The dietary questionnaire was used to establish dietary practices. Table 2 presents the results. More than half of the respondents (64.2\%) obtained food through buying. Only $21.2 \%$ reported as having some food restrictions or allergies that made them avoid some foods. More than half of the respondents (55.1\%) reported poor levels of appetite. The most skipped meal was lunch whereby $25.2 \%$ reported skipping. Under meal preparation, $35.8 \%$ of the respondents reported as having their children prepare their meals. On the number of meals consumed per day $41.2 \%$ consumed two meals per day.

Table 3 Respondents' Dietary Practices

\begin{tabular}{|c|c|c|}
\hline Characteristic & Category & $\%(n)[N=274]$ \\
\hline \multirow[t]{4}{*}{ Sources of food } & Home garden & $29.2(80)$ \\
\hline & Buying & $64.2(176)$ \\
\hline & Donations & $6.2(17)$ \\
\hline & Others & $4.0(1)$ \\
\hline \multirow[t]{2}{*}{ Food restrictions } & Yes & $21.2(58)$ \\
\hline & No & $78.8(216)$ \\
\hline \multirow[t]{3}{*}{ Levels of appetite } & Poor & $55.1(151)$ \\
\hline & Fair & $23.4(64)$ \\
\hline & Good & $21.5(59)$ \\
\hline \multirow[t]{5}{*}{ Meal skipping } & Breakfast & $8.4(23)$ \\
\hline & Lunch & $25.2(69)$ \\
\hline & Supper & $9.1(25)$ \\
\hline & Rarely & $39.8(109)$ \\
\hline & More than one & $17.5(48)$ \\
\hline
\end{tabular}




\begin{tabular}{|c|c|c|}
\hline \multirow{4}{*}{ Meals preparation } & Self & $23.7(65)$ \\
\cline { 2 - 3 } & Children & $35.8(98)$ \\
\cline { 2 - 3 } & Friend & $8.8(24)$ \\
\cline { 2 - 3 } & Spouse & $13.9(38)$ \\
\cline { 2 - 3 } Number of meals consumed per & In-laws & $7.7(21)$ \\
\cline { 2 - 3 } day & Others & $10.2(28)$ \\
\cline { 2 - 3 } & One & $17.5(48)$ \\
\cline { 2 - 3 } & Two & $41.2(113)$ \\
\cline { 2 - 3 } & Three & $26.6(73)$ \\
\cline { 2 - 3 } & Four & $13.9(38)$ \\
\cline { 2 - 3 } & More than four & $7.0(2)$ \\
\hline
\end{tabular}

\subsection{Association of Demographic Characteristics and Malnutrition}

Chi-square tests were conducted between the socio demographic characteristics and the nutrition status of the respondents. The results are displayed in Table 4. The results showed that gender $(p=0.000)$ and education level $(p=0.035)$ were significant. Cross tabulation showed that men and those with low education were more likely to be malnourished.

Table 4 Association of Demographic Characteristics and Malnutrition

\begin{tabular}{|l|c|c|c|}
\hline \multicolumn{1}{|c|}{ Characteristic } & $\begin{array}{c}\text { Chi-square value } \\
\left(\boldsymbol{\chi}^{\mathbf{2}} \mathbf{)}\right.\end{array}$ & Degrees of freedom (df) & Significance (p) \\
\hline Gender & 110.344 & 274 & $0.000^{* * *}$ \\
\hline Marital Status & 3.121 & 274 & 0.373 \\
\hline Education Level & 22.187 & 274 & $0.035^{* * *}$ \\
\hline
\end{tabular}

\subsection{Association of Dietary Practices and Malnutrition}

To find out the relationship between dietary practices and malnutrition among the elderly in Kiambu County, Chi-square tests were conducted between the indicators of dietary practices and the nutrition status of the respondents. Results in Table 5 show that skipping of meals $(p=0.003)$ and number of meals $(p=0.042)$ were significant. Cross tabulation showed that respondents who had less than 3 meals and who skipped at least one meal were more likely to be malnourished.

Table 5 Association of Dietary Practices and Malnutrition

\begin{tabular}{|l|c|c|c|}
\hline Characteristic & Chi-square value $(\boldsymbol{\chi} \mathbf{2})$ & Degrees of freedom (df) & Asymp. Sig. (p) (2-sided) \\
\hline Food sources & 12.316 & 274 & 0.655 \\
\hline Food restrictions & 6.942 & 274 & 0.074 \\
\hline Appetite & 6.215 & 274 & 0.102 \\
\hline Meal skipping & 13.643 & 274 & $0.003^{* * *}$ \\
\hline Meals Preparation & 8.752 & 274 & 0.188 \\
\hline Number of meals & 8.187 & 274 & $0.042^{* * *}$ \\
\hline
\end{tabular}




\section{Discussion}

The study found that a high prevalence of malnutrition. The results also showed poor dietary practices. There was a relationship between dietary practices and malnutrition. Skipping of meals and number of meals were significant. Respondents who had less than 3 meals and who skipped at least one meal were more likely to be malnourished. This result is in consonance with findings of Vassilakou et al. (2020) that the daily number of full-course meals consumed was associated with malnutrition risk among free-living elderly in the community of an urban municipality of Attica. These findings are similar to those of Beck and Ovesen (2004) who established that participants who were skipping meals had a lower BMI, energy and protein intake (all $\mathrm{p}<0.001$ ) and a higher prevalence of negative protein balance $(\mathrm{p}$ $<0.01$ ), than the other residents. This result is however in disagreement with findings of Fávaro-Moreira et al. (2016) who established that poor appetite and needing assistance to eat were statistically significant eating-related risk factors for malnutrition, whereas the ability to eat independently was related to the improvement of the nutritional status.

\section{Conclusion}

Most of the elderly persons in Kiambu County are malnourished and a large number are at risk of malnutrition. The high prevalence of malnutrition in the sample can be attributed to poor dietary practices. Majority of elderly persons do not have 3 meals signalling inadequate access to food and poor household food security. There is a need therefore to strengthen access to food for elderly persons. This study recommends an increase in food supplementation efforts by the county government to old people. The study also recommends that the government ought to lower the age for cash transfer and increase the amount to ensure that the elderly are not able to afford food but have food security and eat well.

\section{Compliance with ethical standards}

\section{Disclosure of conflict of interest}

No conflict of interest.

\section{Statement of informed consent}

Informed consent was obtained from all individual participants included in the study.

\section{References}

[1] Adams N, Bowie A, Simmance N, Murray M, Crowe T. Recognition by medical and nursing professionals of malnutrition and risk of malnutrition in elderly hospitalised patients. Nutr Diet. 2008; 65(2): 144-150.

[2] Munoru FK. Dietary And Care Practices, Morbidity And Nutritional Status Of The Elderly In Igembe South, Meru County, Kenya (Doctoral dissertation, Kenyatta University). 2018.

[3] Bore C. Prevalence ofUnder-Nutrition andFood Security amongtheElderly inUasin Gishu County, Kenya.

[4] Krishnamoorthy Y, Vijayageetha M, Kumar SG, Rajaa S, Rehman T. Prevalence of malnutrition and its associated factors among elderly population in rural Puducherry using mini-nutritional assessment questionnaire. Journal of family medicine and primary care. 2018; 7(6): 1429.

[5] Chalermsri C, Herzig van Wees S, Ziaei S, Ekström EC, Muangpaisan W, Rahman SM. Exploring the experience and determinants of the food choices and eating practices of elderly Thai people: A qualitative study. Nutrients. 2020; 12(11): 3497.

[6] Zainudin N, Hamirudin AH, Rahman NAA, Sidek S. Malnutrition risk and perception on dietary practices among elderly living in agricultural settlements. Nutrition \& Food Science. 2019.

[7] Krok-Schoen JL, Price AA, Luo M, Kelly OJ, Taylor CA. Low dietary protein intakes and associated dietary patterns and functional limitations in an aging population: a NHANES analysis. The journal of nutrition, health \& aging. $2019 ; 23(4), 338-347$.

[8] Aeberhard C, Stanga Z, Leuenberger M. Practical scores for the detection of malnutrition. . Ther Umsch. 2014; 71(3): 141-7. 
[9] Govindaraju T, Sahle BW, McCaffrey TA, McNeil JJ, Owen AJ. Dietary Patterns and Quality of Life in Older Adults: A Systematic Review. Nutrients. 2018; 10(8): 971.

[10] Shlisky J, Bloom DE, Beaudreault AR, Tucker KL, Keller HH, Freund-Levi Y, Fielding RA, Cheng FW, Jensen GL, Wu D, Meydani SN. Nutritional Considerations for Healthy Aging and Reduction in Age-Related Chronic Disease. Advances in nutrition (Bethesda, Md.). 2017; 8(1): 17-26.

[11] Reddy S, Anitha M. Culture and its influence on nutrition and oral health. Biomedical \& Pharmacology Journal. 2015; 8(SpecialOct): 613.

[12] Bede F, Cumber SN, Nkfusai CN, Venyuy MA, Ijang YP, Wepngong EN, Kien ATN. Dietary habits and nutritional status of medical school students: the case of three state universities in Cameroon. The Pan African Medical Journal. 2020; 35.

[13] Nana A, Zema T. Dietary practices and associated factors during pregnancy in northwestern Ethiopia. BMC pregnancy and childbirth. 2018; 18(1): 1-8.

[14] Agarwalla R, Saikia AM, Baruah R. Assessment of the nutritional status of the elderly and its correlates. Journal of Family \& Community Medicine. 2016; 39-43.

[15] Agarwalla R, Saikia MA, Baruah R. Assessment of the Nutritional Status of the Elderly and its Correlates. J Family Community Med. 2015; 22(1): 39-43.

[16] Ahmed T, Haboubi N. Assessment and management of nutrition in older people and its importance to health. 2010; 4-10.

[17] Al-Rasheed R, AR, AJ, Alrashidi H, Almaimany Bayan, et al. Malnutrition in elderly and its relation to depression. International Journal of Community Medicine and Public Health. 2018; 5(6): 2156-2160.

[18] American Psychological Association. Fact Sheet: Age and Socioeconomic Status . American Psychological Association Journal. 2017; 1-4.

[19] Boateng N, Jeptanui N. Promoting Healthy Nutrition among the Elderly Living in a Service Home . Centria Journal on Public Health. 2016; 2-7.

[20] Carpenter CJ. A meta-analysis of the effectiveness of health belief model variables in predicting behavior. Health Communication. 2010; 25(8): 661-669.

[21] Comp CE, Comp SJ. Nutrition and the Elderly: A Selected Annotated Bibliography for Nutrition and Health Professionals. Bibliographies of Literature and Agriculture No. 2014; 34.

[22] County Governement of Kiambu. (2018, February 18th). Demographic Features. KIambu County, Central Province, Kenya. 2018.

[23] Demling R, DeSanti L. Involuntary weight loss and protein-energy malnutrition: diagnosis and treatment. 2001.

[24] Donini L, Scardella P, Piombo L, Neri B, Asprino R, Proietti A, et al. Malnutrition in elderly: social and economic determinants. . J Nutr Health Aging. 2013; 17(1): 9-15.

[25] Elia M. The malnutrition advisory group consensus guidelines for the detection and management of malnutrition in the community. . Nutr Bull. 2001; 26(1): 81-83.

[26] Ghimire S, Baral BK, Callahan K. Nutritional assessment of community dwelling older adults in rural Nepal. Nutrition among the Elderly. 2017; 23-26.

[27] Grundy E, Holt G. The Socioeconomic Status of Older Adults: How Should we Measure it in Studies of Health Inequalities . Journal of Epidemiology \& Community Health. 2016; 25.

[28] Joymati O, Minita N, Bishwalata R, Agatha G. Assessment of nutritional status among elderly population in a rural area in Manipur: community-based cross-sectional study. International Journal of Community Medicine and Public Health J. 2018; 5(7): 3125-3129.

[29] Kaiser M, Bauer J, Rämsch C, Uter W, Guigoz Y, Cederholm T, et al. Frequency of malnutrition in older adults: a multinational perspective using the mini nutritional assessment. J Am Geriatr Soc. 2010; 58(9): $1734-8$.

[30] Kamiya Y, Sofroniou N. Socio-Demographic Characteristics of Older People in Ireland . The Irish Longitudinal Study on Ageing. 2016; 24-28.

[31] Khagayi S. Socio-economic Status and Elderly Adult Mortality in Rural Ghana: Evidence from the Navrongo DSS . Johannesburg Journal. 2009; 12-34. 
[32] Khagayi S. Socio-economic Status and Elderly Adult Mortality in Rural Ghana: Evidence from the Navrongo DSS. Johannesburg Journal. 2018; 12-34.

[33] Kohrs MB, Czajka-Narins D, Nordstrom J. Factors Affecting Nutritional Status of the Elderly. Nutrition, Aging, and the Elderly. 2016; 305-333.

[34] Leslie W, Hnakey C. Aging, Nutritional Status and Health. Healthcare Journal. 2015; 648-658.

[35] Luger E, Haider S, Kapan A, Schindler K, Lackinger C. Association Between Nutritional Status and Quality of Life in (Pre) Frail Community-Dwelling Older Persons . The Journal of Frailty \& Aging. 2016; 141-147.

[36] Ngatia E, Gathece L, Macigo F, Mulli T, Mutara L, Wagaiyu E. Nutritional and oral health status of an elderly population in Nairobi. East African Medical Journal. 2008; 85(8): 378.

[37] Odunga P. Factors Affecting the Nutrition Satus of the Pokot and the Tugen Elderly in the Drought Prone Areas of Baringo District. Masters Thesis (University of Nairobi). 2004; 23-45.

[38] Olayiwola I, Ketiku A. Socio-demographic and nutritional assessment of the elderly Yorubas in Nigeria. Asia Pac J Clin Nutr. 2006; 15(1): 95-101.

[39] Saini N. The Factors Influencing the Food Choice and Nutritional Status of Elderly People Living Freely on Merseyside . Liverpool John Moores. 2012; 34-45.

[40] Sameh E. Assessment of nutritional status of elderly populations in rural Minia, Egypt. International Journal on Public health \& preventive Medicine. 2017; 234.

[41] Senterfitt JW, Long A, Shih M, Teutsch S. How Social and Economic Factors Affect Health . Social Determinants of Health. 2013; 5-8.

[42] Söderström L. Nutritional status among older people Risk factors and consequences of malnutrition. Clinical Nutrition and Metabolism. 2013; 10-16.

[43] Tessfamichael D, Gete AA, Wassie MM. High Prevalence of Undernutrition among Elderly People in Northwest Ethiopia: A Cross Sectional Study. Journal of Nutritional Health \& Food Science. 2014.

[44] Urbina Torija JR, FM, García SM, Torres BL, Torrubias F. Depressive symptoms in the elderly. Prevalence and associated factors. . Gac Sanit [PubMed]. 2007; 21: 37-42.

[45] Vivanti A, Ward N, Haines T. Nutritional status and associations with falls, balance, mobility and functionality during hospital admission. . J Nutr Health Aging. 2011; 15(5): 388-91.

[46] Wada H. Problems and strategies in the treatment of mental disorders in elderly patients with physical illness. Nihon Ronen Igakkai Zasshi [PubMed]. 2000; 37: 885-8.

[47] WHO. Nutrition for older persons. 2015.

[48] Zulkowski KC. Comparison of nutritional risk between urban and rural elderly. . Ostomy Wound Management. 2004; 50(5): 46-8. 